\title{
O DESAFIO DE ANALISAR SOLUTOS BÁSICOS POR CROMATOGRAFIA LÍQUIDA EM MODO REVERSO: ALGUMAS ALTERNATIVAS PARA MELHORAR AS SEPARAÇÕES
}

\author{
Endler Marcel Borges* \\ Departamento de Ciência de Alimentos, Faculdade de Engenharia de Alimentos, Universidade Estadual de Campinas, CP 6121, \\ 13083-970 Campinas - SP, Brasil
}

Karen Goraieb e Carol H. Collins

Instituto de Química, Universidade Estadual de Campinas, CP 6154, 13084-971 Campinas - SP, Brasil

Recebido em 15/8/11; aceito em 25/11/11; publicado na web em 20/1/12

\begin{abstract}
THE CHALLENGES OF THE ANALYSIS OF BASIC SOLUTES BY REVERSED PHASE LIQUID CHROMATOGRAPHY: SOME POSSIBLE APPROACHES FOR IMPROVED SEPARATIONS. This review considers some of the difficulties encountered with the analysis of basic solutes using reversed-phase chromatography, such as detrimental interaction with stationary phase silanol groups. Methods of overcoming these problems in reversed-phase separations, by judicious selection of the stationary phase and mobile phase conditions, are discussed. Developments to improve the chemical and thermal stability of stationary phases are also reviewed. It is shown that substantial progress has been made in the manufacturing of stationary phases, enabling their use over a wide variety of experimental conditions. In addition, general measures to significantly extend their lifespan are discussed.
\end{abstract}

Keywords: reversed-phase stationary phases; column classification; chemical and thermal stability.

\section{INTRODUÇÃO}

A cromatografia líquida (LC, liquid chromatography) tem ampla aceitação como técnica analítica, sendo utilizada em muitas áreas da ciência. O modo mais usado desta técnica é o modo reverso (RP-LC, reversed phase liquid chromatography) devido às suas inúmeras vantagens, tais como uso de fases móveis de menor custo e menor toxicidade; rápido equilíbrio da coluna após a mudança de fase móvel; possibilidade da condução de separações no modo de eluição por gradiente, resultando em maior rapidez e melhor separação nas análises; boa repetibilidade dos tempos de retenção; amplo campo de aplicação, devido à possibilidade de separação de compostos de diferentes polaridades, massas molares e funcionalidades, dentre outras. ${ }^{1,2}$ Por sua vez, mais de $70 \%$ dos fármacos disponíveis no mercado são bases e a RP-LC é a técnica mais utilizada para analisar solutos básicos, ${ }^{1,3}$ mas alguns problemas acontecem quando solutos básicos são analisados por RP-LC e, por esta razão, esta revisão se dedica a apresentar estes problemas e a fornecer algumas alternativas para superá-los, contribuindo com outras revisões produzidas pelo nosso grupo de pesquisa a respeito da RP-LC. ${ }^{4-9}$

Em RP-LC o principal objetivo é obter separação dos solutos, que é avaliada através da resolução $\left(\mathrm{R}_{\mathrm{s}}\right)$, que determinada o grau de separação entre dois picos adjacentes. A resolução pode ser expressa em função da eficiência $\left(\mathrm{N}_{2}\right)$, da seletividade $(\alpha)$ e do fator de retenção do segundo pico $\left(\mathrm{k}_{2}\right)$, com a aproximação de que ambos os picos têm aproximadamente a mesma largura à meia altura. De acordo com a equação $R_{s}=\left(\sqrt{N_{2}} / 4\right)\left(k_{2} / k_{2}+1\right)(\alpha-1 / \alpha)$ o aumento do fator de retenção resulta em melhores resoluções apenas quando os solutos forem pouco retidos (fatores de retenção menores que 1) e fatores de retenção maiores que 10 aproximam o termo da equação $(\mathrm{k} / \mathrm{k}+1)$ à unidade. Enquanto dobrar a eficiência da separação resulta em um aumento da resolução de $\sqrt{2}$ (41\%), um aumento na seletividade de 1,05 para 1,10 faz com que a resolução aumente em duas vezes. Desta forma existem duas maneiras de se aumentar a resolução: aumentar a eficiência e aumentar a seletividade da separação. ${ }^{10}$

*e-mail: marcelborgesb@gmail.com
É interessante ressaltar que, ao longo deste texto, serão discutidas alternativas para se alterar a retenção dos solutos e não a seletividade. Fica subentendido que alterar a retenção dos solutos permite que a seletividade seja alterada. Outro parâmetro muito importante é a assimétrica dos picos, sendo que este não é incluído nas fórmulas para cálculo da resolução, mas picos assimétricos podem comprometer a resolução e levar a diversos inconvenientes, como baixa reprodutibilidade nos tempos de retenção e nas áreas dos picos, entre outros. ${ }^{11,12}$

Existem várias alternativas para aumentar a eficiência de uma separação, como usar colunas com maior comprimento, resultando em maiores tempos de análise, ou usar colunas de mesmo comprimento recheadas com partículas de menor diâmetro, resultando em maiores pressões. ${ }^{13-15}$ No caso de solutos básicos, o uso de fases estacionárias especialmente designadas para tal fim pode aumentar a eficiência e a seletividade da separação, sem qualquer aumento no tempo de análise ou na pressão gerada pelo sistema cromatográfico. Por sua vez, em RP-LC a seletividade de solutos básicos pode ser alterada variando-se parâmetros cromatográficos como o $\mathrm{pH}$ da fase móvel, o tipo de tampão, a concentração de tampão e a fase estacionária utilizada. Porém, surgem algumas dúvidas de como estas variáveis podem alterar a seletividade de uma separação e a vida útil de uma fase estacionária.

Outras dúvidas também surgem quanto à seleção de uma fase estacionária adequada para se analisar solutos básicos em condições compatíveis com a espectrometria de massas em tandem acoplada à cromatografia líquida (LC-MS/MS, liquid chromatogtaphy tandem mass spectrometry) uma vez que todos os testes disponíveis na literatura utilizam tampão fosfato $20 \mathrm{mmol} / \mathrm{L}$. Como, por exemplo, se uma fase estacionária fornece picos simétricos na análise da amitriptilina em fase móvel 50:50 (v/v) metanol:tampão fosfato $(20 \mathrm{mmol} / \mathrm{L}$; $\mathrm{pH} 2,5)$, pode-se esperar que esta fase estacionária forneça picos simétricos em metanol: ácido fórmico $(\mathrm{pH} ; \mathrm{pH} 2,5)$ ? Pode-se ainda perguntar se uma fase estacionária que fornece picos simétricos em fase móvel ácida ( $\mathrm{pH}$ 2,5) com tampão fosfato $20 \mathrm{mmol} / \mathrm{L}$ ou ácido fórmico $0,1 \%$ fornece picos simétricos em fase móvel neutra $(\mathrm{pH} \sim 7)$ com tampão fosfato $20 \mathrm{mmol} / \mathrm{L}$ ? Os catálogos dos fabricantes sempre indicam que as fases estacionárias comercializadas por eles são mais 
apropriadas que as comercializadas pelo concorrente para analisar solutos básicos, mas quais propriedades cromatográficas devem ser levadas em conta na escolha da fase estacionária mais apropriada? Se o catálogo de um fabricante afirma que a fase estacionária $\mathrm{X}$ fornece picos mais assimétricos e melhor eficiência para nortriptilina que a fase estacionária $\mathrm{Y}$, que fornece picos mais simétricos e maior eficiência que a fase estacionária $X$ para amitriptilina, qual destas fases estacionárias deve ser escolhida para analisar o dextrometorfano em um antigripal?

Atualmente, a LC-MS/MS se torna uma técnica cada vez mais utilizada, ${ }^{16}$ que não permite o uso de tampões não voláteis, como fosfato, e baixas concentrações de tampão na fase móvel aumentam a sensibilidade do detector. ${ }^{16,17}$ Desta forma, muitos métodos conduzidos utilizando fase móvel com tampão fosfato $20 \mathrm{mmol} / \mathrm{L}$ tiveram de ser adaptados para a técnica de LC-MS/MS, substituindo tampões não voláteis por tampões voláteis (geralmente acetato ou formato de amônia e ácido fórmico ou acético) a concentrações de $1 \mathrm{mmo} / \mathrm{L}$ ou $0,1 \%$, o que vem gerando algumas dúvidas acerca dos efeitos causados pela mudança na concentração e/ou do tipo de tampão na retenção e seletividade de solutos básicos.

Existem vários testes disponíveis ${ }^{18-23}$ na literatura para se avaliar as propriedades cromatográficas, como os testes SRM $870^{24,25}$ e de Tanaka, ${ }^{26,27}$ mas que informações podem trazer a respeito de uma fase estacionária e como estes testes podem ser usados para selecionar uma fase estacionária mais apropriada para uma dada separação?

Desta forma, esta revisão se dedica a responder algumas das principais questões dos usuários da RP-LC, descrevendo como os fatores pH da fase móvel, concentração de tampão e o tipo de tampão afetam a retenção e a seletividade de solutos básicos e, por sua vez, como estes fatores afetam a estabilidade das fases estacionárias. A escolha de uma fase estacionária adequada para analisar solutos básicos pode poupar esforços no desenvolvimento de um método analítico e, por esta razão, foi dada especial atenção aos testes cromatográficos utilizados para avaliar e classificar as fases estacionárias.

\section{FASES ESTACIONÁRIAS ESPECIALMENTE DESIGNADAS PARA ANÁLISE DE SOLUTOS BÁSICOS}

A maioria das fases estacionárias utilizadas em RP-LC são preparadas pela reação de silanos com os silanóis na superfície da sílica, sendo os silanos mais utilizados do tipo $\mathrm{XSi}\left(\mathrm{R}_{1}\right)_{2} \mathrm{R}_{2}$, onde $\mathrm{X}$ é um cloro ou alcóxido, os grupos $\mathrm{R}_{1}$ são grupos hidrofóbicos com cadeia alquílica pequena (tais como, metil, etil e propril), o grupo $R_{2}$ é uma cadeia alquílica extensa, como 8 (C8) ou 18 (C18) carbonos. ${ }^{10}$

A funcionalização da sílica com silanos do tipo $\mathrm{XSi}\left(\mathrm{R}_{1}\right)_{2} \mathrm{R}_{2}$ resulta em apenas uma ligação entre o silano e a superfície da sílica e ainda hoje é o processo mais utilizado para preparar fases estacionárias para RP-LC. No entanto, a firma Waters, entre outras, passou a funcionalizar a sílica com silanos do tipo $(\mathrm{Cl})_{2} \mathrm{SiR}_{1} \mathrm{R}_{2}$, que resulta em duas ligações entre o silano e a superfície da sílica; as fases estacionárias produzidas com esta tecnologia foram comercializadas com os nomes SunFire ${ }^{28}$ e Atlantis. ${ }^{29}$ Atualmente, a Waters passou a utilizar silanos do tipo $(\mathrm{Cl})_{3} \mathrm{SiR}_{2}$, que proporcionam três ligações entre o silano e a sílica e as fases estacionárias preparadas com esta tecnologia são comercializadas com o nome Atlantis T3. ${ }^{29}$ Outro maneira de funcionalizar a superfície da sílica é o uso de silanos bidentados do tipo $\mathrm{ClSiR}_{1} \mathrm{R}_{2}\left(\mathrm{CH}_{2}\right)_{3} \mathrm{SiR}_{1} \mathrm{R}_{2} \mathrm{Cl}$ e uma das fases estacionárias produzidas com esta tecnologia é comercializadas pela Agilent com o nome de Zorbax Extend (Figura 1S, material suplementar). ${ }^{30,31}$

Em RP-LC, os solutos neutros são retidos por interações hidrofóbicas com as cadeias hidrofóbicas ligadas covalentemente à superfície da sílica. Diferentes seletividades podem ser obtidas quando diferentes tipos de ligantes reagem com a superfície do mesmo tipo de sílica. O uso de uma fase estacionária do tipo $\mathrm{C} 18$, ao invés de uma fase $\mathrm{C} 8$, resulta no aumento da retenção, enquanto que o uso de uma fase $\mathrm{C} 4$ resulta na diminuição da retenção. Já o uso de fases estacionárias fenil ou ciano resulta em seletividades distintas daquelas obtidas com fases estacionárias $\mathrm{C} 4, \mathrm{C} 8$ e C18, devido à existência de interações $\pi$ - $\pi$ além das interações hidrofóbicas presentes em ligantes alquílicos (Figura 2S, material suplementar). ${ }^{32}$

Quando os solutos básicos são analisados por RP-LC, ocorrem interações destes com os silanóis residuais presentes na superfície da sílica, ${ }^{32-34}$ na qual os solutos podem ser retidos por interações puramente iônicas com os silanóis residuais ionizados, por interações puramente hidrofóbicas com as cadeias hidrofóbicas covalentemente ligadas à sílica ou por interações em sítios que combinam interações hidrofóbicas e iônicas de maneira sinérgica, formando sítios altamente retentivos (Figura 3S, material suplementar) ${ }^{34}$ Desta forma, a seletividade pode ser alterada pelo tipo de ligante utilizado para preparar a fase estacionária, por exemplo, na separação de uma mistura de solutos ácidos, básicos e neutros, o uso de uma fase estacionária do tipo fenil fornece seletividade distinta da fase estacionária C18, enquanto uma fase estacionária fluoro-fenil fornece seletividade ainda mais distinta de uma fase estacionária C18 do que uma fase estacionária fenil (Figura 4S, material suplementar). ${ }^{35}$ Por outro lado, fases estacionárias preparadas com o mesmo silano e com sílicas diferentes podem apresentar seletividades distintas, devido às diferentes interações que os solutos podem fazer com os silanóis residuais, por exemplo, as fases estacionárias Acquity CSH C18 e Acquity BEH C18, da Waters, são preparadas com o mesmo silano $\left(\mathrm{Cl}_{3} \mathrm{SiC}_{18} \mathrm{H}_{37}\right)$ e com sílicas diferentes, implicando em seletividades similares para os solutos neutros e distintas para os solutos ácidos e básicos (Figura 4S, material suplementar). ${ }^{35}$ Resumindo, fases estacionárias fornecem seletividades distintas tanto pelo tipo de ligante utilizado para funcionalizar a superfície da sílica quanto pelo tipo de sílica utilizado para preparar a fase estacionária. ${ }^{35,36}$

Diversas tentativas foram feitas no intuito de reduzir a quantidade de silanóis residuais na superfície da sílica. ${ }^{37}$ Uma delas consistiu na funcionalização sucessiva da superfície da sílica, primeiramente com silanos de cadeia alquílica longa e, depois, com silanos de cadeia alquílica curta (esta última etapa é chamada de reação de capeamento). ${ }^{1,10,37-39}$ Porém, mesmo após sucessivas reações de funcionalização da sílica, mais de $50 \%$ dos silanóis não são derivatizados, devido ao impedimento estérico criado pelos ligantes..$^{37-39}$

Outra tentativa foi reduzir a concentração de metais, tais como, Al, Fe, Ti, Na, K, Ca e Mg, presentes na sílica, que aumentam a acidez dos silanóis residuais. ${ }^{37-39}$ A sílica que era utilizada para preparar fases estacionárias para RP-LC no início da década de 90 possuía altas concentrações de metais e as fases estacionárias preparadas com este tipo de sílica ofereciam baixa eficiência e picos assimétricos na análise de solutos básicos, devido à alta acidez e não homogeneidade na população dos silanóis residuais. ${ }^{1,18}$ Cabe ressaltar que a assimetria de pico e a baixa eficiência são atribuídas à existência de fenômenos distintos de retenção, proporcionados pela existência de silanóis com graus de acidez distintos. ${ }^{40}$ Atualmente, as fases estacionárias são preparadas utilizando sílicas com baixa concentração de metais e, por isso, os silanóis de sua superfície apresentam acidez semelhante..$^{1,37-39}$

Por fim, a tentativa que se mostrou mais útil foi a preparação da sílica híbrida, ${ }^{41}$ na qual alguns dos silanóis são substituídos por grupos orgânicos como metil ou pontes de etano. Esta tecnologia foi desenvolvida pela Waters que comercializa as fases estacionárias que possuem ligações $-\mathrm{Si}-\mathrm{CH}_{3} \mathrm{e}-\mathrm{Si}-\mathrm{CH}_{2}-\mathrm{CH}_{2}-\mathrm{Si}$ - em suas estruturas, sob os nomes XTerra ${ }^{\mathrm{TM} 42}$ e XBridge ${ }^{\mathrm{TM}},{ }^{43,44}$ respectivamente. As empresas Phenomenox e Kromasil também comercializam fases estacionárias com tecnologia híbrida, com os nomes de Gemini-NX ${ }^{45,46}$ e Eternity, ${ }^{47}$ respectivamente. Em 2010, a Waters lançou uma nova tecnologia de 
preparação de fases estacionárias chamada Charged Surface Hybrid (CSH) que é comercializada com o nome de XSelect, ${ }^{48}$ que são melhores para analisar solutos básicos do que as fases estacionárias híbridas conforme atesta o fabricante (Figura 4S, material suplementar).

Embora a sílica e a sílica híbrida sejam os suportes mais utilizados para preparar fases estacionárias para RP-LC, a ZirChrom ${ }^{49-53}$ comercializa fases estacionárias preparadas pelo recobrimento do óxido de zircônio com polímeros (polibutadieno ou poliestireno) ou pela grafitização do óxido de zircônio, com subsequente derivatização com grupos alquila. No entanto, estas fases estacionárias são mais retentivas para compostos básicos que as fases à base de sílica ou sílica híbrida, devido à formação de sítios que combinam interações hidrofóbicas e de troca iônica ${ }^{40}$ (este tipo de mecanismo de retenção ${ }^{28}$ é mostrado na Figura $5 \mathrm{~S}$, material suplementar). ${ }^{28}$ Um exemplo disto é o fato da fase estacionária ZirChrom PDB ser mais retentiva para as alquíl $p$-benzilaminas que a zircônia sem recobrimento polimérico. ${ }^{32}$

Outros exemplos de fases estacionárias não usuais são as desenvolvidas em nosso grupo de pesquisa, que são preparadas pela imobilização de polissiloxanos sobre a superfície da sílica. Estas fases estacionárias apresentam retenção diferenciada para solutos básicos, devido à sinergia entre interações hidrofóbicas e iônicas, aliada à alta área superficial da sílica. ${ }^{54-59}$

\section{COMO O pH, O TIPO DE TAMPÃO E A CONCENTRAÇÃO DE TAMPÃO AFETAM A SELETIVIDADE EM RP-LC}

O pH, o tipo de tampão e a concentração de tampão são variáveis que influenciam fortemente a seletividade. Estas variáveis não só podem ser usadas para manipular a seletividade como, em alguns casos, alterar o pH da fase móvel, o tipo e a concentração de tampão pode ser uma necessidade.

A retenção de qualquer tipo de soluto em RP-LC pode ser alterada pela percentagem $(20,30,50,80 \%$ etc. $)$ e pelo tipo de modificador orgânico (acetonitrila, metanol). ${ }^{10,60}$ Além disso, quando os solutos a serem separados são ionizáveis, a retenção também é alterada pelo pH da fase móvel, uma vez que o grau de ionização dos solutos e dos silanóis residuais depende do $\mathrm{pH}$ da fase móvel. Normalmente, a retenção de solutos básicos em RP-LC segue um comportamento semelhante ao ilustrado na Figura 1a. Na região A, o pH da fase móvel é duas unidades menor que o $\mathrm{pKa}$ do soluto teste, o qual se encontra na sua forma iônica. Por isso, este é pouco retido por interações hidrofóbicas. Na região ao redor de B, o pH da fase móvel está entre uma unidade a mais e uma unidade a menos que o pKa do soluto e pequenas variações no $\mathrm{pH}$ resultam em grandes variações na retenção devido a variações no grau de ionização do soluto. Na região $\mathrm{C}, \mathrm{o}$ $\mathrm{pH}$ da fase móvel é duas unidades maior que o pKa do soluto, que se encontra como base livre, fazendo com que a retenção atinja seu valor máximo, uma vez que o soluto não ionizado será mais retido por interações hidrofóbicas do que em sua forma iônica.

A seletividade de solutos ácidos segue um comportamento oposto ao dos solutos básicos, como mostrado na Figura $1 b .{ }^{10} \mathrm{Na}$ região A, o $\mathrm{pH}$ da fase móvel é duas unidades menor que o pKa do soluto ácido, que se encontra protonado, e a retenção deste soluto atinge um valor máximo. Já ao redor de B, o pH da fase móvel é uma unidade maior ou menor que o $\mathrm{pKa}$ do soluto e pequenas variações no $\mathrm{pH}$ da fase móvel resultam em grandes variações no valor do fator de retenção. $\mathrm{Na}$ região $\mathrm{C}, \mathrm{o} \mathrm{pH}$ da fase móvel é duas unidades maior que o $\mathrm{pKa}$
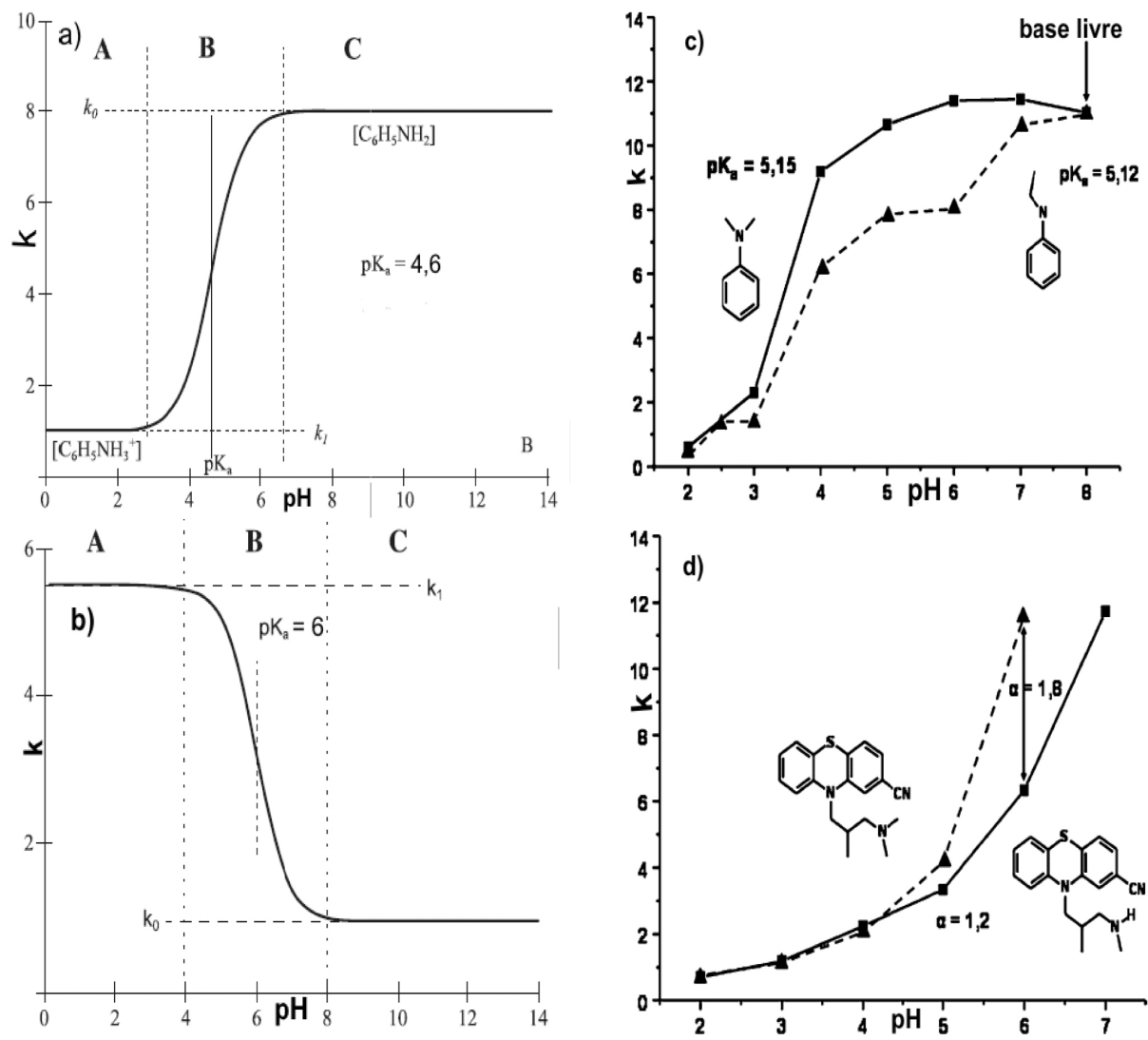

Figura 1. Variação da retenção em função do $\mathrm{pH}$ : a) variação da retenção de uma base fraca (anilina) em função do pH da fase móvel; b) variação da retenção de um soluto ácido em função do $\mathrm{pH}$ da fase móvel; c) influência do $\mathrm{pH}$ da fase móvel sobre a seletividade da $N, N$-dimetilanilina (pKa 5,15) e $\mathrm{N}$-etilanilina (pKa 5,12); d) influência do pH da fase móvel sobre a seletividade da $\mathrm{N}$-desmetilciamemazina e ciamemazina (ambos os solutos com $\mathrm{pK}>9$ ). Condiçôes para c) e d) coluna: Symmetry SH 18. Fase móvel: acetonitrila:tampão fosfato $20 \mathrm{mmol} / \mathrm{L}: a ́ g u a ~ 35: 35: 30$ (v/v/v). Adaptadas das refs. 10 e 61 
do soluto. Nestes valores de $\mathrm{pH}$ o soluto está desprotonado, por isso, fica pouco retido por interações hidrofóbicas e a retenção atinge seu valor mínimo.

No exemplo da Figura 1a, ${ }^{10}$ o soluto teste é a anilina, que é uma base fraca com pKa 4,6, que realiza poucas interações de troca iônica com os silanóis residuais na fase estacionária. Neste caso, a retenção é governada apenas pelo grau de ionização do soluto, a exemplo do que ocorre com os solutos ácidos que dificilmente interagem com os silanóis residuais, mas quando os solutos a serem separados têm $\mathrm{pKa}>5$, podem realizar interações de troca iônica com os silanóis residuais da fase estacionária e a seletividade destes solutos também é governada pelo grau de ionização dos silanóis na superfície da fase estacionária. ${ }^{39,58} \mathrm{Na}$ Figura 1c, ${ }^{61}$ a N,N-dimetilanilina e N-etilanilina, que possuem hidrofobicidade semelhante, coeluem em pH 2 e são pouco separadas em $\mathrm{pH} 3$, uma vez que, nesta faixa de $\mathrm{pH}$, ambos os solutos e os silanóis residuais se encontram $100 \%$ protonados e, com isso, as interações hidrofóbicas e iônicas são suprimidas. Os compostos começam a ser bem separados em pH 5 e 6, onde os solutos e os silanóis residuais estão parcialmente ionizados e a separação ocorre devido a interações dos solutos com os silanóis residuais. No entanto, em $\mathrm{pH} 8$, os solutos se encontram na forma de bases livres, e novamente a separação não ocorre devido à supressão das interações com os silanóis residuais, sendo que os dois solutos, com hidrofobicidade semelhante, não podem ser separados apenas por interação hidrofóbicas.

A Figura $1 \mathrm{~d}^{61}$ mostra que a separação dos solutos desmetilciamemazina e ciamemazina, que diferem em suas estruturas apenas por um grupo metil, não é possível em $\mathrm{pH}<5$ pois, nesta faixa de $\mathrm{pH}$, os solutos e os silanóis residuais se encontram protonados e as interações hidrofóbicas e iônicas são suprimidas, enquanto que, em
$\mathrm{pH} \geq 5$, os solutos começam a ser desprotonados, fazendo com que os fatores de retenção aumentem. Na faixa de $\mathrm{pH}$ estudada (2 a 7), aplicando-se a Equação de Henderson-Hasselbalch aos valores de pKa da desmetilciamemazina e da ciamemazina ( $\mathrm{pKa}>9$ ) obteve-se que em $\mathrm{pH} \geq 7$ ambos os solutos estão protonados. Então, por que se observa aumento da retenção quando a fase aquosa tem $\mathrm{pH} \geq 5$ ?

A resposta à essa pergunta é que o $\mathrm{pH}$ da fase móvel $\left({ }_{\mathrm{w}}^{\mathrm{s}} \mathrm{pH}\right.$, modificador orgânico:solução tampão) é diferente do $\mathrm{pH}$ da fase aquosa $\left({ }_{w}{ }^{w} \mathrm{pH}\right)$, após a adição de modificador orgânico, ${ }^{62-64}$ assim como o pKa dos solutos em solução aquosa é diferente do pKa dos solutos na fase móvel ( $\left.{ }_{w}^{5} \mathrm{pK}\right) .{ }^{65,66} \mathrm{O} \mathrm{pH}$ da fase móvel após a adição de modificador orgânico varia em função do tipo de tampão (fosfato, carbonato, borato, tris, citrato etc.), do tipo de modificador orgânico e da percentagem de modificador orgânico. Fases móveis preparadas com tampões fosfato, borato, citrato, formato e acetato têm ${ }_{w}{ }^{s} \mathrm{pH}$ maior que o pH da fase aquosa após a adição de modificador orgânico, enquanto fases móveis preparadas com tampões com grupos amino (amônia, tris, tricina, trietilamina, piperazina etc.) têm ${ }_{w}{ }_{\mathrm{w}}^{\mathrm{p}} \mathrm{HH}$ menor que pH da fase aquosa após a adição de modificador orgânico. A adição de metanol à solução aquosa causa maiores variações no $\mathrm{pH}$ da fase móvel $\left({ }_{\mathrm{w}}^{\mathrm{s}} \mathrm{pH}\right)$ do que a adição de quantidades iguais de acetonitrila, exemplos na Tabela $1 .{ }^{62-64}$ Por sua vez, o aumento da percentagem de modificador orgânico na fase móvel reduz o pKa dos solutos (Tabela $1 \mathrm{~S}$, material suplementar). ${ }^{65,66}$

Desta forma, quando se troca tampão fosfato por tampão amônia, para tornar o método compatível com LC-MS/MS, a fase móvel preparada com tampão amônia possui menor ${ }_{w}{ }^{s} \mathrm{pH}$ do que a fase móvel preparada com fosfato, o que resulta em solutos básicos menos retidos e solutos ácidos mais retidos na fase móvel preparada com tampão amônia. (Figura 6S, material suplementar). ${ }^{64}$

Tabela 1. Variação do ${ }_{w}^{\mathrm{s}} \mathrm{pH}$ em função do tipo de tampão, do tipo de modificador orgânico e da percentagem de modificador orgânico. Todos os valores foram mesurados a $20^{\circ} \mathrm{C}$ (valores retirados das refs. 62-64)

\begin{tabular}{|c|c|c|c|c|c|c|}
\hline \multirow[b]{2}{*}{ \% de metanol na fase móvel } & \multicolumn{6}{|c|}{$\mathrm{pH}$} \\
\hline & $0 \%$ & $20 \%$ & $40 \%$ & $50 \%$ & $60 \%$ & $80 \%$ \\
\hline $\mathrm{H}_{3} \mathrm{PO}_{4}-\mathrm{H}_{2} \mathrm{PO}_{4^{-}}$ & 2,11 & 2,63 & 3,09 & 3,35 & 3,68 & 4,3 \\
\hline $\mathrm{H}_{2} \mathrm{PO}_{4}^{-}-\mathrm{HPO}_{4}^{2-}$ & 7,20 & 7,55 & 8,04 & 8,36 & 8,75 & 9,58 \\
\hline $\mathrm{H}_{3} \mathrm{Cit}-\mathrm{H}_{2} \mathrm{Cit}^{-}$ & 3,13 & 3,44 & 3,84 & 4,07 & 4,30 & 4,77 \\
\hline $\mathrm{H}_{2} \mathrm{Cit}-\mathrm{Cit}_{2}-$ & 4,76 & 5,12 & 5,53 & 5,8 & 6,10 & 6,64 \\
\hline $\mathrm{HCit}^{2-} \mathrm{Cit}^{3-}$ & 6,40 & 6,83 & 7,39 & 7,66 & 7,96 & 8,60 \\
\hline $\mathrm{HAc}-\mathrm{Ac}^{-}$ & 4,76 & 5,05 & 5,43 & 5,66 & 5,92 & 6,46 \\
\hline $\mathrm{NH}_{4}^{+}-\mathrm{NH}_{3}$ & 9,24 & 9,11 & 8,97 & 8,89 & 8,82 & 8,63 \\
\hline$\%$ de acetonitrila na fase móvel & $0 \%$ & $20 \%$ & $40 \%$ & $50 \%$ & $60 \%$ & $80 \%$ \\
\hline $\mathrm{H}_{3} \mathrm{PO}_{4}-\mathrm{H}_{2} \mathrm{PO}_{4^{-}}$ & 2,11 & 2,28 & 2,55 & & 2,54 & \\
\hline $\mathrm{H}_{2} \mathrm{PO} 4-\mathrm{HPO}_{4}{ }^{2-}$ & 7,2 & 7,48 & 7,66 & & 8,01 & \\
\hline $\mathrm{H}_{3} \mathrm{Cit}-\mathrm{H}_{2} \mathrm{Cit}-$ & 3,13 & 3,15 & 3,43 & & 3,64 & \\
\hline $\mathrm{H}_{2} \mathrm{Cit}-\mathrm{Cit} 2-$ & 4,76 & 4,32 & 4,65 & & 5,01 & \\
\hline $\mathrm{HCit}^{2-} \mathrm{Cit}^{3-}$ & 6,4 & 6,55 & 6,84 & & 7,28 & \\
\hline $\mathrm{HAc}-\mathrm{Ac}^{-}$ & 4,76 & 5,39 & 5,8 & & 6,47 & \\
\hline $\mathrm{NH}_{4}^{+}-\mathrm{NH}_{3}$ & 9,24 & 9,79 & 9,39 & & 9,25 & \\
\hline $\mathrm{H}_{2} \mathrm{CO}_{2}-\mathrm{HCO}_{2}^{-}$ & 3,72 & 3,96 & 4,4 & & 4,87 & \\
\hline Piperazina $\left(\mathrm{pKa}_{1}\right)$ & 5,37 & 5,26 & 5,19 & & 5,06 & \\
\hline Piperazina $\left(\mathrm{pKa}_{2}\right)$ & 9,76 & 9,62 & 9,53 & & 9,42 & \\
\hline Tris & 8,08 & 7,94 & 7,85 & & 7,72 & \\
\hline Borato & 9,23 & 9,85 & 10,43 & & 11,00 & \\
\hline $\mathrm{HCO}_{3}^{-}-\mathrm{CO}_{3}{ }^{2-}$ & 10,35 & 10,82 & 11,31 & & 11,62 & \\
\hline
\end{tabular}


Um comportamento ideal semelhante ao da Figura 1a dificilmente é observado para bases com $\mathrm{pKa}>7$, devido a interações secundárias dos silanóis residuais com os solutos básicos. Por sua vez, os solutos ácidos não realizam interações secundárias com os silanóis residuais e um comportamento semelhante ao descrito na Figura $1 \mathrm{~b}$ é comumente observado. Portanto, quanto menor o número de silanóis residuais na superfície da fase estacionária, mais próxima do ideal descrito na Figura 1a será a variação da retenção em função do $\mathrm{pH} .{ }^{55}$ Por exemplo, Walter et al. ${ }^{67}$ estudaram como a retenção de solutos ácidos (paracetamol e ibuprofeno) e básicos (doxepina, imipramina, nortriptilina e lidocaína) varia em função do $\mathrm{pH}$ (medido na fase aquosa), utilizando fase móvel metanol:tampão fosfato $20 \mathrm{mmol} / \mathrm{L} 65: 35$ (v/v) em uma fase estacionária XTerra MS C18. Neste estudo, o ibuprofeno (pKa 5) apresentou um comportamento quase ideal, como descrito na Figura $1 \mathrm{~b}$, e a região B é observada entre pH 5-7 e não entre $\mathrm{pH}$ 4-6, como o esperado pelo pKa do ibuprofeno. Isto ocorre porque os solutos ácidos têm seu pKa elevado com a adição de modificador orgânico, ${ }^{62,68}$ enquanto que a retenção do paracetamol (pK 10,2) começa a decrescer em $\mathrm{pH} 9$. Para os solutos básicos, a região $\mathrm{B}$ e o ponto em que a retenção dos solutos se torna constante foram observados em valores de $\mathrm{pH}$ cerca de uma unidade a menos que o pKa dos solutos (lidocaína $~ 7,9$; nortriptilina $\sim 10,2$; doxepina e imipramina 9,5).${ }^{65,66}$ Portanto, para maximizar a retenção dos solutos básicos não é necessário realizar a análise em valores extremos de $\mathrm{pH}$, por exemplo, a nortriptilina tem $\mathrm{pKa} \sim 10,2$, mas a retenção deste soluto se torna constante $\mathrm{em} \mathrm{pH} 9$, porque $\mathrm{o}_{w}{ }_{\mathrm{w}}^{\mathrm{s}} \mathrm{pH}$ da fase móvel é maior que o $\mathrm{pH}$ da fase aquosa e o pKa dos solutos na fase móvel ( $\left.{ }_{w}{ }^{\mathrm{s}} \mathrm{pKa}\right)$ é menor que o pKa em água.

Walter et al. ${ }^{67}$ também demonstraram como o $\mathrm{pH}$ da fase móvel pode ser utilizado para manipular a seletividade, sendo que em $\mathrm{pH} \leq 6$ a separação da nortriptilina e da imipramina é pobre, enquanto a separação entre estes solutos é fácil em $\mathrm{pH}>6$. Porém, em pH 7 a lidocaína coelui com a imipramina e em $\mathrm{pH}>9$ a doxepina elui próximo à nortriptilina, mostrando que em alguns casos não é vantajoso maximizar as interações hidrofóbicas mantendo os solutos básicos desprotonados (Figura 7S, material suplementar).

Nas fases estacionárias preparadas pela imobilização do poli( metiloctilsiloxano $)^{54,55,58,59}$ e poli(metiltetradecilsiloxano) $)^{56,57}$ sobre a superfície da sílica ou nas fases estacionárias ZirChrom, ${ }^{40-53}$ que apresentam uma grande quantidade de zirconóis residuais, a retenção de solutos básicos é dominada por interações sinérgicas entre os sítios capazes de fazerem interações iônicas e a porção hidrofóbica da fase estacionária. ${ }^{32,34}$ Estas fases estacionárias retêm fortemente solutos básicos, em uma faixa de pH entre 6 e 8, na qual os silanóis residuais (ou zirconóis no caso do zircônia) estão desprotonados e os solutos protonados. A redução do $\mathrm{pH}$ a valores inferiores a 6 resulta na protonação dos sítios capazes de fazerem interações de troca iônica e o aumento do $\mathrm{pH}$ a valores superiores a 8 resulta na desprotonação dos solutos, causando, em ambos os casos, a redução dos fatores de retenção.

Quanto maior o número de sítios capazes de fazerem interações de troca iônica na fase estacionária (silanóis livres na sílica e zirconóis na zircônia) maior será a variação da seletividade quando se troca tampão fosfato por um tampão amino. Por exemplo, Borges e Collins ${ }^{55}$ avaliaram a retenção de solutos básicos (amitriptilina, nortriptilina, propranolol etc.) em duas fases estacionárias comerciais, quimicamente ligadas e preparadas com sílica de alta pureza e em uma fase estacionária preparada pela imobilização do poli(metiloctilsiloxano) sobre a sílica. Nesse trabalho, as fases estacionárias comerciais apresentaram pequena redução (em geral, de 5\%) nos fatores de retenção dos compostos básicos ao serem testadas com fases móveis (metanol:tampão (pH 8; 20 mmol/L) 80:20 (v/v)) tamponadas com fosfato ou tricina, enquanto que a fase estacionária preparada pela imobilização do poli(metiloctilsiloxano) sobre a sílica reteve os solutos básicos, em média, $70 \%$ mais em fase móvel tamponada com tricina do que uma tamponada com fosfato. ${ }^{55}$

Normalmente, as concentrações de tampão na fase móvel têm um efeito desprezível em RP-LC, mas no caso das fases estacionárias ZirChrom, o aumento da concentração de tampão na fase móvel resulta em uma brutal redução na retenção dos solutos básicos, por exemplo, em fase móvel metanol:tampão fosfato a pH 6, 55:45 (v/v), o aumento da concentração de tampão, de 15 para $50 \mathrm{mmol} / \mathrm{L}$, faz com que o fator de retenção da $p$-butilbenzilamina seja reduzido de 54,33 para 17,53. Enquanto que com a fase estacionária comercial ACE C18, preparada com sílica isenta de alta pureza, o mesmo aumento da concentração de tampão resulta em uma redução desprezível no fator de retenção da $p$-butilbenzilamina, de 9,86 para 9,69.49

Quanto maior a quantidade de silanóis residuais em uma fase estacionária, maior será a retenção de solutos básicos quando a concentração de tampão na fase móvel for baixa. ${ }^{49,51,52,54-59}$ Desta forma, ao se usar uma fase estacionária que apresenta muitos silanóis livres em sua superfície, a redução da concentração de tampão na fase móvel fará com que a retenção de compostos básicos seja excessiva. Mesmo no caso de fases estacionárias com uma pequena quantidade de silanóis residuais, a retenção de solutos básicos poderá ser excessiva caso a concentração de tampão seja inferior a $10 \mathrm{mmol} / \mathrm{L}$. Por exemplo, Euerby et al. ${ }^{69}$ mostraram que em uma fase estacionária especialmente designada para analisar solutos básicos (Fluophase PFP da Hypersil), a diminuição da concentração do tampão fosfato na fase móvel (acetonitrila:tampão fosfato 90:10 (v/v) $(\mathrm{pH} 2,7)$ ) de 10 para $1 \mathrm{mmol} / \mathrm{L}$ proporcionou um aumento excessivo no fator de retenção da nortriptilina, de 3 (concentração de tampão: $10 \mathrm{mmol} / \mathrm{L}$ ) para 20 (concentração de tampão: $1 \mathrm{mmol} / \mathrm{L}$ ). Ao se diminuir ainda mais a concentração do tampão, para $0,1 \mathrm{mmol} / \mathrm{L}$, verificou-se que o fator de retenção da nortriptilina aumentou para 70, mostrando que a análise de solutos básicos em concentrações diminutas de tampão é condição desafiadora, mesmo para fases estacionárias modernas especialmente designadas para este tipo de análise.

Outro problema que pode surgir quando se usam baixas concentrações de tampão na fase móvel é a assimetria dos solutos básicos. Chan Leach et al. ${ }^{70}$ demonstraram que com as fases estacionárias, preparadas com as sílicas comercializadas no final da década de 80, o aumento da concentração de tampão na fase móvel resulta em picos mais simétricos. McCalley ${ }^{1,3,71}$ recomendou o desenvolvimento de métodos para analisar solutos básicos em fases móveis ácidas, quando fosse necessário utilizar baixas concentrações de tampão, porque em fases móveis ácidas, a maior parte dos silanóis estão protonados assim como os solutos, resultando picos mais assimétricos e a retenção varia menos em função da concentração de tampão do que em fases móveis neutras. Cabe aqui ressaltar que fases estacionárias híbridas também apresentam picos assimétricos em fase móvel ácida com baixa concentração de tampão, como é mostrado na Figura $4 \mathrm{~S}$, material suplementar ${ }^{35}$ e, ainda hoje, poucas fases estacionárias fornecem picos simétricos na análise de solutos básicos com baixas concentrações de tampão na fase móvel.

\section{ESTABILIDADE DAS FASES ESTACIONÁRIAS}

Como já discutido, as separações de compostos básicos e ácidos podem necessitar de fases móveis ácidas ou alcalinas. Os mesmos silanóis que interagem com solutos básicos são os responsáveis pela instabilidade da sílica em meio alcalino, uma vez que os hidróxidos na fase móvel atacam os silanóis residuais, ocasionando a dissolução da sílica e a degradação da fase estacionária..$^{5,6,9,37,38,72-75}$ Por sua vez, a sílica é um material extremamente estável em meio ácido, mas as ligações siloxano no ligante utilizado para modificar a sílica quimicamente (Si-C) são hidrolisadas em meio ácido. .,6, $, 937,38,75,76^{-1}$ 


\section{Estabilidade em fase móvel alcalina}

Os testes de estabilidade são feitos em condições semelhantes às condições comumente usadas ( $\mathrm{pH}$ da fase aquosa entre 2 e 8 , concentração de tampão entre 5 e $25 \mathrm{mmol} / \mathrm{L}$ e temperaturas entre 20 e $40{ }^{\circ} \mathrm{C}$ ) ou em condições extremas para acelerar a degradação da fase estacionária ( $\mathrm{pH}$ da fase aquosa extremamente ácido em 0,5 a 1,5 ou extremamente alcalino em 10 a 14, concentração de tampão de 50 a $200 \mathrm{mmol} / \mathrm{L}$ e temperaturas entre 23 e $150{ }^{\circ} \mathrm{C}$ ), sendo que o primeiro caso representa melhor a estabilidade das fases estacionárias. A degradação da fase estacionária é avaliada em função da passagem de fase móvel pela coluna, sendo representada em volumes de coluna $(\mathrm{Vc})$ ou pelo tempo em que a fase móvel passa pela coluna $\mathrm{s}^{5,6,37,38,75}$

Muitas tentativas foram feitas para aumentar a estabilidade das fases estacionárias em condições alcalinas. A primeira, consistiu em aumentar o recobrimento da sílica; porém, não é possível funcionalizar $100 \%$ dos silanóis da sílica, mesmo após sucessivas reações de capeamento. Desta forma, mesmo as fases estacionárias com um alto grau de funcionalização dos silanóis residuais são instáveis em meio alcalino, por exemplo, a fase estacionária Luna C18 (2), que apresenta um alto grau de funcionalização de seus silanóis, se degrada em meio alcalino (Figura 8S, material suplementar) após a passagem de $4700 \mathrm{Vc}$ de fase móvel alcalina, 45:55 (v/v) acetonitrila-fosfato de potássio $(\mathrm{pH} 10 ; 20 \mathrm{mmol} / \mathrm{L}) .{ }^{49}$

A segunda tentativa para aumentar a estabilidade das fases estacionárias foi o preparo de fases estacionárias híbridas, que possuem menos silanóis residuais e são mais estáveis que as fases estacionárias preparadas com sílica não híbrida. Claessens e van Straten ${ }^{37}$ demonstraram que a fase estacionária híbrida XTerra MS C18 é mais estável em fase móvel alcalina (50:50 (v/v) metanol-carbonato ( $\mathrm{pH}$ $10 ; 100 \mathrm{mmol} / \mathrm{L})$ ) que outras fases estacionárias à base de sílica não híbrida (Nucleosil C18, Hypersil C18, Nova-Pak C18, Lichrospher C18, Zorbax ODS, Zorbax-Rx-C18), exceto pela fase estacionária Zorbax Extend-C18, preparada pela funcionalização da sílica com silanos bidentados, que se mostrou mais estável que a fase estacionária XTerra MS C18.

A comparação da estabilidade de fases estacionárias híbridas, XBridge C18 e XTerra MS C18, com outras fases estacionárias preparadas com sílica não híbrida, Gemini C18, Luna C18(2), YMC Pro C18 e Zorbaz Extend C18, utilizando um teste que avalia a perda de eficiência do acenafeteno frente ao tempo de exposição das fases estacionárias a uma fase móvel trietilamina ( $\mathrm{pH} 10 ; 50 \mathrm{mmol} / \mathrm{L})$ a 50 ${ }^{\circ} \mathrm{C}$, mostrou que a fase XTerra MS C18 é mais estável que as fases estacionárias à base de sílica, sendo que perde $70 \%$ de eficiência após $30 \mathrm{~h}$ de teste, enquanto as demais fases estacionárias à base de sílica perdem $70 \%$ de eficiência após $20 \mathrm{~h}$. Enquanto isso, a fase estacionária XBridge C18 não apresentou nenhuma perda de eficiência após 200 $\mathrm{h}$ de teste (Figura 9S, material suplementar). ${ }^{77}$

Em outro teste, ${ }^{48}$ que consistiu em avaliar a perda de retenção da decanofenona em função da exposição da fase estacionária frente à passagem de uma fase móvel de hidróxido sódio $20 \mathrm{mmol} / \mathrm{L}(\mathrm{pH}$ $\sim 12,3$ ) em horas, foram empregadas diversas fases estacionárias híbridas (XTerra, XBridge, XSelect e Gemini NX com funcionalidades $\mathrm{C} 18$, fenil e fenil-hexil) e observou-se a seguinte ordem de estabilidade XBridge $>$ XSelect $>$ Gemini NX $>$ XTerra. Este estudo também mostrou que as fases estacionárias C18 são mais estáveis que as fases estacionárias fenil e fenil-hexil, por exemplo, as fases estacionárias XSelec C18 e XBridge C18 são mais estáveis que as fases XSelect fenil-hexil e XBridge fenil, respectivamente. ${ }^{48}$

O tipo de soluto teste utilizado também pode levar a resultados diferentes nos testes de estabilidade, por exemplo, a comparação entre as fases estacionárias Eternity $\mathrm{C} 18$ e XBridge C18 através de um teste que avalia a perda de eficiência da amitriptilina e da predinisola em função do tempo de exposição à fase móvel alcalina acetonitrila:carbonato de amônia ( $\mathrm{pH} 10 ; 10 \mathrm{mmol} / \mathrm{L})$, a $40{ }^{\circ} \mathrm{C} .{ }^{47} \mathrm{O}$ experimento que utilizou a amitriptilina como soluto teste apontou que as duas fases têm a mesma estabilidade e o que utilizou a predinisola como soluto teste mostrou que a fase estacionária Eternity C18 é mais estável. ${ }^{47}$

É necessário salientar que certos fatores, como o $\mathrm{pH}$ da fase móvel e a concentração e o tipo de tampão utilizado, têm influências significativas na dissolução da sílica. Fases móveis preparadas com tampões amino são menos agressivas do que as preparadas com tampões inorgânicos e fases estacionárias preparadas com sílica podem ser utilizadas em meio alcalino com tampões amino, porque fases móveis preparadas com amino tampões têm menor ${ }_{w}^{5} \mathrm{pH}$ do que fase móveis preparadas com tampões inorgânicos (Tabela 1). Por exemplo, uma fase móvel metanol:tampão fosfato (pH 7; $250 \mathrm{mmol} / \mathrm{L}$ ) 20:80 (v/v) causa maior degradação da fase estacionária que uma fase móvel metanol:tampão tris (pH 7; 250 mmol/L) 20:80 (v/v) (Figura 10S, material suplementar). ${ }^{72}$

As fases estacionárias têm maior estabilidade quando utilizadas com maior quantidade de modificador orgânico. Por exemplo, Borges e Collins ${ }^{59}$ observaram que uma fase estacionária, preparada pela imobilização do poli(metiloctilsiloxano) sobre a superfície da sílica, é mais estável em fase móvel metanol: tampão fosfato ( $\mathrm{pH} \mathrm{11,20}$ $\mathrm{mmol} / \mathrm{L}$ ) 80:20 (v/v) do que com uma fase móvel 50:50 (v/v). Neste caso, o aumento da percentagem de modificador orgânico diminui a solubilidade da sílica na fase móvel.

Outro fator importante quanto à degradação da fase estacionária é a temperatura. Temperaturas iguais ou maiores a $60{ }^{\circ} \mathrm{C}$ aumentam a solubilidade da sílica na fase móvel, inclusive em meio neutro. ${ }^{5,6,9,37,38,59,73,74}$ Por exemplo, quando a fase estacionária Zorbax Rx-C18 é submetida a um teste de estabilidade com a fase móvel acetonitrila:tampão fosfato (pH 7; $250 \mathrm{mmol} / \mathrm{L})$ 20:80 (v/v), praticamente nenhuma sílica é dissolvida quando o teste é feito a $40{ }^{\circ} \mathrm{C}$, enquanto o teste feito a $60{ }^{\circ} \mathrm{C}$ resulta em uma dissolução acentuada da fase estacionária (Figura 11S, material suplementar). ${ }^{74}$ No entanto, esta fase estacionária pode ser submetida ao mesmo teste a $60{ }^{\circ} \mathrm{C}$ com uma concentração de tris de $50 \mathrm{mmol} / \mathrm{L}$ sem que qualquer dissolução na sílica seja evidenciada; quando a concentração de tampão tris é aumentada para $250 \mathrm{mmol} / \mathrm{L}$, a sílica começa a se dissolver, mas muito menos que nos testes que utilizavam fosfato a 50 e $250 \mathrm{mmol} / \mathrm{L}$ (Figura 12S, material suplementar). Desta forma, fases estacionárias à base de sílica podem ser utilizadas com fases móveis alcalinas quando se faz uso de tampões orgânicos, temperatura ambiente e concentrações diminutas de tampão. ${ }^{59}$ Por exemplo, a fase estacionária Zorbax XDB-C8 não apresenta nenhuma perda de eficiência para o propanolol mediante purga com mais de 30.000 volumes de coluna com fase móvel: metanol:tampão trietilamina e 1-metil-peperidina ( $\mathrm{pH} 11 ; 17 \mathrm{mmol} / \mathrm{L}$ ) 55:45, v/v a $23^{\circ} \mathrm{C}$, enquanto o teste conduzido com tampão fosfato destruiu a fase estacionária após $5.000 \mathrm{Vc}$ de purga. ${ }^{72}$

Teutenberg et al. ${ }^{73}$ estudaram as estabilidades das fases estacionárias Zorbax SB C-18, Nucleodur Gravity C-18, Gemini C18, Gemini NX C18, PLRP-S, pHidelity C18, Blaze 200 C-18, Pathfinder MR, Zorbax StableBond, Ascentis C-18, XBridge C-18, YMC Pack Pro C-18 e ZirChrom PBD. Utilizaram um teste que consiste em purgar as colunas sucessivamente com fase móvel não tamponada (metanol:água 10:90 (v/v)), ácida (metanol:tampão fosfato (pH 2,2; $20 \mathrm{mmol} / \mathrm{L}$ ) 10:90 (v/v)) e alcalina (metanol:tampão fosfato (pH 12; $20 \mathrm{mmol} / \mathrm{L})$ 10:90 (v/v)). Cada fase estacionária foi submetida a 5 ciclos de purga com cada uma das fases móveis. Cada ciclo consistia em purgar a fase estacionária com fase móvel por $5 \mathrm{~h}$, a $150{ }^{\circ} \mathrm{C}$ e ao final de cada $5 \mathrm{~h}$ as fases estacionárias eram re-equilibradas em fase móvel metanol:tampão fosfato (pH 7; $20 \mathrm{mmol} / \mathrm{L})$ 65:35 (v/v) 
a $23{ }^{\circ} \mathrm{C}$ e avaliadas com a mistura teste de Neue. ${ }^{78} \mathrm{O}$ resultado deste teste mostrou que a fase estacionária Gemini NX, à base de sílica híbrida, não sofre nenhuma degradação frente ao teste não tamponado, sofre uma pequena degradação com o teste ácido e é completamente degradada frente ao primeiro ciclo do teste alcalino. Por sua vez, as fases estacionárias à base de sílica (Gemini C18 e Zorbax StableBond C18) se degradaram rapidamente com o teste não tamponado (Figura 13S, material suplementar). A fase estacionária XBridge, à base de sílica híbrida, se mostrou inalterada após o teste não tamponado e ao teste ácido, sendo completamente degradada após o primeiro ciclo com o teste alcalino. A fase estacionária ZirChrom PDB, à base de zircônia, foi degradada por todos os testes, mas a degradação causada pelo teste alcalino foi menor que a observada pelo teste alcalino com as fase estacionárias Gemini-NX e XBridge. (Figura 14S, material suplementar). Desta forma, o trabalho de Teutenberg et al. ${ }^{73}$ reforça as informações fornecidas pela Waters ${ }^{77}$ de que a fase estacionária XBridge é mais estável que as fases estacionárias Gemini-NX e ZirChrom-PDB a altas temperaturas em fase móvel não tamponada e ácida.

\section{Estabilidade em fase móvel ácida}

Grupos funcionais com cadeia mais curta, tais como os utilizados nas reações de capeamento, $\mathrm{C} 4$, fenil, perfluorfenil e cianopropil, são mais susceptíveis à hidrólise que ligantes com cadeias mais longas, tais como C8 e C18. ${ }^{37,38}$ A substituição dos grupos laterais nos grupos ligados covalentemente à superfície da sílica por grupos mais volumosos, como isopropil (iPr), aumentam a estabilidade da fase estacionária frente à hidrólise em meio ácido. Por exemplo, em um teste de estabilidade que avalia a perda de retenção do 1-fenileptano em função da purga com fase móvel 50:50 (v/v) acetonitrila-TFA $0,1 \%$ a $50{ }^{\circ} \mathrm{C}$, as fases estacionárias preparadas com os silanos $\mathrm{ClSi}\left(\mathrm{CH}_{3}\right)_{2} \mathrm{C}_{3} \mathrm{H}_{6} \mathrm{CN}$ e $\mathrm{ClSi}\left(\mathrm{CH}_{3}\right)_{2} \mathrm{C}_{3} \mathrm{H}_{7}$ perderam $60 \%$ da retenção do 1-fenileptano após purga de 6.000 volumes de coluna, enquanto as fases estacionárias preparadas com os silanos $\mathrm{ClSi}(\mathrm{iPr})_{2} \mathrm{C}_{3} \mathrm{H}_{6} \mathrm{CN}$ e $\mathrm{ClSi}(\mathrm{iPr})_{2} \mathrm{C}_{3} \mathrm{H}_{6} \mathrm{CN}$ não apresentaram nenhuma perda de retenção ao final do teste, porque os grupos iPr protegem, por impedimento estérico, a ligação $\mathrm{Si}-\mathrm{C}$ que prende o silano à superfície da sílica (Figura 15S, material suplementar). ${ }^{37,38,75}$

Em um teste realizado pela Waters, ${ }^{77}$ que levou em conta a perda da retenção do butilparabeno (soluto teste) em função do tempo de purga com uma fase móvel de ácido trifluoracético $1 \%$ a $80{ }^{\circ} \mathrm{C}$, indicou que a fase estacionária Zorbax SB (StableBond), preparada com um silano de cadeias laterais volumosas, é mais estável que fases estacionárias preparadas com silanos que podem se ligar a mais de um silanol na superfície do suporte, obtendo-se a seguinte ordem de estabilidade: ClSi(iso-but) ${ }_{2} \mathrm{C}_{18} \mathrm{H}_{37}<\mathrm{Cl}_{3} \mathrm{SiC}_{18} \mathrm{H}_{37}<\mathrm{Cl}_{2} \mathrm{Si}\left(\mathrm{CH}_{3}\right) \mathrm{C}_{18} \mathrm{H}_{37}$ $<\mathrm{Cl}\left(\mathrm{CH}_{3}\right)_{2} \mathrm{C}_{18} \mathrm{H}_{37}$ (Figura 9Sb, material suplementar).

\section{TESTES CROMATOGRÁFICOS}

Nos primórdios da RP-LC, as avaliações dos parâmetros eficiência e assimetria foram feitas pelos próprios fabricantes de fases estacionárias, usando-se compostos aromáticos simples (tais como, tolueno, naftaleno, acenafteno etc). Posteriormente, diversos testes cromatográficos foram introduzidos para avaliar as propriedades cromatográficas das fases estacionárias. Entretanto, que informações estes testes podem fornecer a respeito das fases estacionárias? Que propriedades devem e podem ser avaliadas com estes testes? Com as informações fornecidas por estes testes é possível escolher uma fase estacionária mais apropriada ou menos apropriada para uma determinada análise? Portanto, esta seção se dedica a responder estas questões, mostrando até que ponto os testes cromatográficos descritos na literatura são úteis na escolha de uma fase estacionária apropriada para analisar solutos básicos.

\section{Teste de Tanaka}

Em 1989, Kimata et al. ${ }^{26}$ publicaram um teste que ainda hoje é largamente utilizado em RP-LC, conhecido como "Teste de Tanaka", que avalia as fases estacionárias frente a seis parâmetros cromatográficos: hidrofobicidade, seletividade metilênica, seletividade estérica, capacidade de fazer ligação de hidrogênio, capacidade de troca iônica a pH 7,6 e capacidade de troca iônica a pH 2,7. Estes parâmetros são obtidos usando 8 solutos diferentes e 4 fases móveis diferentes. ${ }^{19-22,26,58}$ Estes parâmetros são obtidos com as seguintes fases móveis: FM1: MeOH: $\mathrm{H}_{2} \mathrm{O}$ (80:20, v/v); FM2: $\mathrm{MeOH}: \mathrm{H}_{2} \mathrm{O}$ (30:70, v/v); FM3: MeOH:tampão fosfato (pH 7,6; $20 \mathrm{mmol} / \mathrm{L})$ 30:70 (v/v) e FM4: MeOH:tampão fosfato (pH 2,7; 20 mmol/L) 30:70 (v/v).

\section{Hidrofobicidade $\left(k_{P e}\right)$}

Este parâmetro mede o recobrimento superficial do suporte cromatográfico. É calculado pelo fator de retenção do pentilbenzeno na FM1. É importante ressaltar que a retenção de um soluto apolar na fase estacionária depende do recobrimento e da área superficial do suporte cromatográfico.

\section{Seletividade metilênica $\left(\mathrm{CH}_{2}\right)$}

É determinada pela razão dos fatores de retenção do pentilbenzeno e do butilbenzeno, $\mathrm{CH}_{2}=\mathrm{k}_{\mathrm{PB}} / \mathrm{k}_{\mathrm{BB}}$ na FM1. Este parâmetro é uma medida de como a fase estacionária separa solutos que diferem em sua estrutura apenas por um grupo $\mathrm{CH}_{2}$.

\section{Seletividade estérica $(T / O)$}

É medida pela razão entre os fatores de retenção do trifenileno e da $o$-terfenila, $\mathrm{T} / \mathrm{O}=\mathrm{k}_{\mathrm{T}} / \mathrm{k}_{\mathrm{O}}$, naFM1. A T/O mede a seletividade estérica, devido ao fato de a hidrofobicidade destes solutos ser semelhante, porém a estrutura deles se diferencia devido ao fato do $o$-terfenil poder mudar sua conformação, enquanto que o trifenileno apresenta uma estrutura rígida.

\section{Capacidade de fazer ligação de hidrogênio (C/P)}

Esta propriedade é obtida pela razão entre os fatores de retenção da cafeína e do fenol, $\mathrm{C} / \mathrm{P}=\mathrm{k}_{\mathrm{C}} / \mathrm{k}_{\mathrm{F}}$ na FM2. $\mathrm{O} \alpha_{\mathrm{C} / \mathrm{F}}$ é uma medida do número de grupos silanóis disponíveis capazes de fazerem ligações de hidrogênio com solutos polares.

\section{Capacidade de troca iônica a pH 7,6 (B/P 7,6)}

Propriedade medida pela razão entre os fatores de retenção da benzilamina (pKa 9,7) e do fenol (pKa 10), B/P 7,6 = $\mathrm{k}_{\mathrm{B}} / \mathrm{k}_{\mathrm{p}}$ a pH 7,6 naFM3. O valor obtido é uma estimativa da capacidade de troca iônica da fase estacionária a $\mathrm{pH} 7,6$, onde a benzilamina e o fenol estão protonados e se espera que os silanóis residuais estejam desprotonados.

\section{Capacidade de troca iônica a pH 2,7 (B/P 2,7)}

Propriedade medida pela razão entre os fatores de retenção da benzilamina e do fenol, B/P pH 2,7 = $\mathrm{k}_{\mathrm{B}} / \mathrm{k}_{\mathrm{F}}$ naFM4. O valor obtido é uma estimativa da capacidade de troca iônica da fase estacionária a $\mathrm{pH} 2,7$. A pH 2,7 a benzilamina e o fenol estão protonados e espera-se que os silanóis residuais também estejam protonados.

Euerby et al. ${ }^{79-81}$ avaliaram 229 fases estacionárias, de diversos tipos, como C8, C18, diol, aqua, grupo polar embutido, fenil, fenil-hexil etc., utilizando o teste de Tanaka. ${ }^{26}$ Dos seis parâmetros avaliados com o teste de Tanaka, observa-se que o parâmetro $\mathrm{CH}_{2}$ não é útil para avaliar as fases estacionárias devido ao seu baixo DPR, de apenas 9\% (DPR alto significa que o parâmetro cromatográfico estudado 
varia consideravelmente de uma fase estacionária para outra). A hidrofobicidade $\left(\mathrm{k}_{\mathrm{Pe}}\right)$ apresenta valores de DPR altos $(74 \%)$ e, por isso, é útil para diferenciar as fases estacionárias, as fases estacionárias com grupos polares como diol, ciano e com grupo polar embutido têm seus valores de hidrofobicidade dentro do primeiro quartil $(1,6)$, devido à menor hidrofobicidade destes ligantes, enquanto fases estacionárias do tipo $\mathrm{C} 8$ e C18 têm valores de hidrofobicidade dentro do quarto quartil $(5,5)$. A seletividade estérica (T/O) tem DPR de $37,1 \%$ e, por isso, não é um parâmetro muito útil para diferenciar as fases estacionárias. A capacidade da fase estacionária de fazer interações polares $(\mathrm{C} / \mathrm{P})$ tem DPR maior que o DPR da hidrofobicidade (89 contra $74 \%$ da hidrofobicidade), e fases estacionárias C8 e C18 apresentam valores de $\mathrm{C} / \mathrm{P}$ próximos à mediana $(0,66)$, enquanto fases estacionárias capazes de fazer interações do tipo $\varpi-\varpi$, do tipo "aqua" (as reações de capeamento são feitas com silanos pequenos que contêm hidroxilas) e preparadas com sílicas contendo impurezas metálicas apresentam valores de $\mathrm{C} / \mathrm{P}$ próximos do quarto quartil $(0,72)$. Os valores de capacidade de troca iônica a pH 7,6 e 2,7 são os parâmetros que têm maior DPR, 206 e 392\%, respectivamente, confirmando que as propriedades de troca iônica, que ocorrem entre os solutos básicos e os silanóis, são as propriedades mais importantes para definir as propriedades cromatográficas das fases estacionárias.

Atualmente, a grande maioria das fases estacionárias, disponíveis comercialmente, é preparada utilizando sílica de alta pureza e, consequentemente, interações menos vigorosas dos solutos básicos com os silanóis residuais na superfície da sílica, além de menor capacidade de troca iônica em meios ácido e neutro. Das 229 fases estacionárias estudadas por Euerby et al..${ }^{81}$ apenas 3 são fases estacionárias preparadas com sílicas com altas concentrações de contaminantes metálicos e, por esta razão, a mediana dos valores para a capacidade de troca iônica é baixa, a grande diferença entre a média e a mediana (B/P 7,6 e B/P 2,7, possuem valores médios de 1,28 e 0,44 e medianas de 0,48 e 0,11 ) se deve à presença de algumas fases estacionárias dentre as 229 estudadas que possuem altas propriedades de troca iônica, como as ZirChrom-PBD, ${ }^{49-53}$ Primesep, ${ }^{82}$ com grupos carboxila embutidos e Hypersil Duet Cation, ${ }^{82}$ que apresentam valores para B/P 7,6 entre 20 e 10 e valores para B/P 2,7 entre 7 e 12.

Kimata et al. ${ }^{26}$ propuseram que fases estacionárias com altas propriedades de troca iônica não são adequadas para a análise de solutos básicos, enquanto as fases estacionárias com baixas propriedades de troca iônica são mais apropriadas, o que é verdadeiro em muitos casos. No entanto, as fases estacionárias ZirChrom, mesmo com altos valores de B/P 7,6 e B/P 2,7, fornecem bons resultados na análise de solutos básicos (alta seletividade, alta eficiência e fatores de assimetria próximos à unidade). ${ }^{49-52}$ As fases estacionárias preparadas pela imobilização do poli(metiloctilsiloxano) $)^{54,55,58,59}$ e poli(metiltetradec ilsiloxano $)^{56,57}$ sobre sílica apresentam baixos valores de troca iônica em fase móvel ácida (valores de B/P 2,7 entre 0-0,1) e altos valores de troca iônica em fase móvel alcalina (valores de B/P 7,6 entre 20-7), mas fornecem bons resultados na análise de solutos básicos.

Se o teste de Tanaka ${ }^{26}$ indica propriedades de troca iônica, qual seria a correlação destas variáveis com os fatores de assimetria de solutos básicos? Se tivéssemos 13 fases estacionárias com valores de troca iônica próximos, qual delas seria mais apropriada para analisar uma mistura de antidepressivos tricíclicos? E se 11 destas fases estacionárias fornecem bons resultados na análise dos antidepressivos tricíclicos, qual destas fases seria mais apropriada para analisar o dextrometorfano em um medicamento antigripal?

Okusa et al. ${ }^{83}$ avaliaram os valores de troca iônica para 13 fases estacionárias do tipo $\mathrm{C} 18$, preparadas com sílica de alta pureza, que apresentaram pequenos valores de troca iônica em fase móvel ácida e neutra, e fatores de assimetria próximos à unidade para benzilamina em pH 2,7 e, em pH 7,6, apenas as fases estacionárias Symmetry
C18 e Luna $5 \mu$ C18(2) (FE I e FE J, respectivamente) apresentaram fatores de assimetria maiores que 1,3 para a benzilamina (Figura 16S, material suplementar).

Quando as mesmas fases estacionárias foram avaliadas frente a uma mistura de antidepressivos (Figura 2A), com fase móvel a pH 7, observou-se que, com as fases estacionárias Inertsil ODS-4, Inertsil ODS-3 e L-Column2 ODS (FE A, FE B e FE C), a mianserina elui depois da amitriptilina, enquanto com a fase estacionária Luna $5 \mu$ C18(2) (FE J) esses solutos coeluem e com todas as outras fases estacionárias, a amitriptilina elui depois da mianserina. A fase estacionária Luna $5 \mu \mathrm{C} 18$ (2) (FE J), que forneceu fatores de assimetria elevados para a benzilamina no teste de Tanaka em $\mathrm{pH}$ neutro, apresentou picos simétricos para os antidepressivos, enquanto a fase estacionária Symmetry C18 (FE I), que tinha apresentado fatores de assimetria ainda mais elevados que a fase estacionária Luna $5 \mu \mathrm{C} 18$ (2) (FE J) para a benzilamina, foi a fase estacionária que apresentou os piores fatores de assimetria para os antidepressivos. ${ }^{83}$ Por fim, as fases estacionárias foram avaliadas com fase móvel a $\mathrm{pH} 7$ frente ao dextrometorfano (Figura 2B) e apenas as fases estacionárias Inertsil ODS-4, Inertsil ODS-3, L-Column2 ODS (FE A, FE B e FE C, respectivamente) apresentaram fatores de assimetria aceitáveis para este soluto e o pior fator assimetria dentre todas as fases estacionárias estudadas foi apresentado pela fase estacionária Symmetry C18 (FE I). ${ }^{83}$
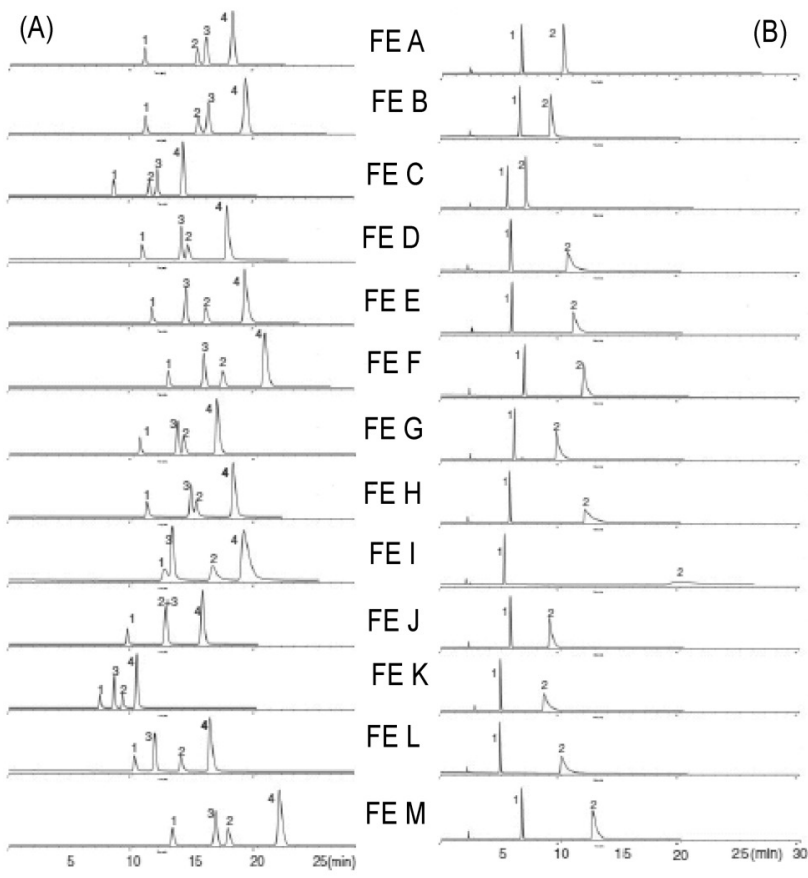

Figura 2. Avaliação de 13 fases estacionárias. (A) Com uma mistura de antidepressivos $(1)=$ imipramina; $(2)=$ amitriptilina; $(3)=$ mianserina; (4) = clomipramina. Fase móvel: acetonitrila:tampão fosfato 60:40 (v/v) $($ pH 7; $20 \mathrm{mmol} / \mathrm{L})$. (B) Com (1) = fenol e (2) = dextrometorfano. Fase móvel: acetonitrila:tampão fosfato 40:60 (v/v) (pH 7; $20 \mathrm{mmol} / \mathrm{L})$. Vazão: 1,0 $\mathrm{mL} / \mathrm{min}$. Temperatura $40{ }^{\circ} \mathrm{C}$. Identificação das fases estacionárias: $F E A=$ Inertsil ODS-4 (GL Sciences); FE B = Inertsil ODS-3 (GL Sciences); $F E C=L$-Column2 ODS (Chemicals Evaluation and Research Institute, Tóquio, Japão); FE D = Capcell Pak C18 MGII (Shiseido, Tóquio, Japão); $F E$ E = YMC-Pack Pro C18 (YMC, Tóquio, Japão); FE F = TSK-GEL ODS$100 \mathrm{~V}$ (Tosoh, Chunam, Japão); FE $G=$ Atlantis T3 d18; FE $H=$ Sunfire C18 (Waters, Milford, EUA); FE I = Symmetry C18 (Waters, Milford, EUA); $F E J=$ Luna $5 \mu$ C18(2) (Phenomenex, Torrance, EUA); FE $K=$ Hypersil GOLD (Thermo Scientific, Waltam, EUA); FE L = Zorbax Eclipse Plus C18 (Agilent Technologies, Santa Clara, EUA) e FE M = Platisil ODS (Dikma, Beijing, China). Adaptada da ref. 83 
Se as fases estacionárias da Figura 2 fossem avaliadas apenas com o teste de Tanaka (Figura 16S, material suplementar), seria impossível observar qual fase estacionária é mais apropriada para analisar compostos básicos, visto que todas elas têm valores de $\mathrm{B} / \mathrm{P}$ 7,6 e B/P 2,7 similares. Quando os fatores de assimetria da benzilamina são incluídos nos resultados, é possível diferenciar apenas as fases Symmetry C18 e Luna $5 \mu$ C18(2) das demais, enquanto que a análise da mistura de antidepressivos com estas fases proporcionou um melhor entendimento da seletividade. A avaliação do fator de assimetria do dextrometorfano mostra que as fases estacionárias Inertsil ODS-4, Inertsil ODS-3, L-Column2 ODS são as mais apropriadas para a análise de solutos básicos. Se uma das 13 fases estacionárias tivesse de ser escolhida para analisar a mistura de antidepressivos apresentada na Figura 2A, levando em conta apenas o fator de assimetria do dextrometorfano, estas fases seriam escolhidas como as melhores alternativas, mas se o alvo da análise fosse separar a amitriptilina da mianserina, as fases estacionárias YMC-Pack Pro C18, TSK-GEL ODS-100 V e Zorbax Eclipse Plus C18 seriam as mais apropriadas. A desvantagem dos testes que classificam as fases estacionárias como "melhores" ou "piores" para analisar solutos básicos é que a maioria deles não fornece nenhuma ideia a respeito da seletividade da fase estacionária. ${ }^{83}$

\section{Teste SRM 870}

Em 2003, o teste SRM 870 foi desenvolvido ${ }^{24,25}$ e consiste na análise de uma mistura teste com 5 solutos (uracila, tolueno, etilbenzeno, quinizarina e amitriptilina) com fase móvel 80:20 (v/v) metanol:tampão fosfato $(\mathrm{pH} 7 ; 20 \mathrm{mmol} / \mathrm{L})$ a $23{ }^{\circ} \mathrm{C}$, a fim de avaliar as fases estacionárias frente aos seguintes parâmetros cromatográficos: hidrofobicidade, medida pelo fator de retenção do etilbenzeno $\left(\mathrm{k}_{\mathrm{E}}\right)$; atividade silanofílica, medida pelo fator de retenção e de alargamento da amitriptilina ( $\mathrm{k}_{\mathrm{ami}}$ e $\mathrm{Tf}_{\mathrm{ami}}$, respectivamente) e a pureza da sílica, medida pelo fator de alargamento da quinizarina $\left(\mathrm{Tf}_{\mathrm{Q}}\right)$. Neste teste, os fatores de separação do etilbenzeno e do tolueno são considerados como constantes e as fases estacionárias apropriadas para analisar solutos básicos devem apresentar picos assimétricos para amitriptilina.

A Farmacopeia Americana ${ }^{25}$ (United States Pharmacopeia, USP) avaliou 108 fases estacionárias com o teste SRM 870, mostrando que os 4 parâmetros cromatográficos avaliados com este teste não estão correlacionados, embora apresentem DPR apreciáveis $\left(\mathrm{k}_{\mathrm{E}}, 43 \% ; \mathrm{k}_{\text {ami }}\right.$, $69 \% ; \mathrm{Tf}_{\text {ami }}, 70 \%$ e $\mathrm{Tf}_{\mathrm{Q}}, 65 \%$ ). Isto significa que esses 4 parâmetros fornecem informações distintas a respeito das propriedades das fases estacionárias, por isso, todos os são importantes na identificação das propriedades cromatográficas. Os fatores de retenção e de assimetria da amitriptilina não estão correlacionados, o que reforça as observações de que fases estacionárias com altas propriedades de troca iônica não fornecem necessariamente resultados ruins para a análise de solutos básicos (Figura 17S, material suplementar).

O DPR do fator de retenção do etilbenzeno (43\%) é menor que o do pentilbenzeno no teste de Tanaka (74\%), provavelmente porque nesse trabalho ${ }^{20}$ foram avaliadas apenas 108 fases estacionárias, enquanto que Euerby et al.$^{81}$ avaliaram 229 fases estacionárias. Por sua vez, os DPR para os fatores de assimetria da amitriptilina e da quinizarina são razoáveis ( $70 \%)$, mas menores do que os obtidos para as propriedades de troca iônica (B/P 7,6 e B/P 2,7) com o teste de Tanaka. No entanto, os fatores de assimetria para amitriptilina observados pela USP ${ }^{25}$ mostram que muitas das fases estacionárias disponíveis comercialmente fornecem altos fatores de assimetria para a amitriptilina, embora os fabricantes afirmem que estas fases estacionárias tenham sido preparadas com sílicas de alta pureza e sejam especialmente designadas para analisar solutos básicos como, por exemplo, a fase estacionária Zorbax Extend-C18 que fornece um
$\mathrm{Tf}_{\text {ami }}$ de 3,4 para a amitriptilina, que é considerado como inaceitável, embora o fabricante afirme que esta fase estacionária é ideal para analisar solutos básicos. ${ }^{30}$ Considerando estes resultados, pode-se afirmar que o teste SRM 870 é útil para avaliar fases estacionárias e que a amitriptilina ainda é um soluto teste eficiente para tal fim, embora o dextrometorfano seja um soluto mais "desafiador" e proporcione uma melhor diferenciação das fases estacionárias, como mostrado na Figura 2B.

\section{Visão geral sobre os testes cromatográficos}

Através de revisões recentes ${ }^{18-23}$ dos diversos testes cromatográficos, verifica-se que a avaliação das fases estacionárias é feita principalmente através do estudo de dois parâmetros cromatográficos: hidrofobicidade e atividade silanofilica. A hidrofobicidade é avaliada pelo fator de retenção de um soluto apolar, enquanto que a atividade silanofílica é estudada através do fator de assimetria de um soluto básico ou do fator de separação entre um soluto básico e um neutro. ${ }^{18-23,58,84-86}$ Neste ponto, cabe ressaltar que o termo atividade silanofílica não é bem definido na literatura, por exemplo, a atividade silanofílica pode ser definida como "se fase estacionária é adequada para analisar solutos básicos", neste caso a atividade silanofílica é avaliada pelo fator de assimetria de um soluto básico, como no teste SRM $870^{24,25}$ e na Figura 2, ou ser definida como a participação dos silanóis residuais na retenção de solutos básicos, sendo avaliada pelo fator de separação entre um soluto básico e um neutro, como no teste de Tanaka ${ }^{26,79-81}$ e na Figura 16S (material suplementar).

Por sua vez, escolher uma fase estacionária para uma determinada aplicação pode ser uma tarefa árdua e muitos fatores devem ser levados em conta, por exemplo, dentre as fases estacionárias XBridge C18, Hypersil Gold C18 e Zorbax Extend C18, qual delas seria a "mais apropriada" para analisar uma mistura de solutos ácidos, básicos e neutros em fase móvel ácida? As três fases estacionárias apresentam valores de $\mathrm{B} / \mathrm{P} 7,6$ e B/P 2,7 pequenos e próximos. ${ }^{81} \mathrm{~A}$ fase estacionária Zorbax Extend C18 apresenta um fator de assimetria de 3,4 para a amitriptilina com o teste SRM 870, enquanto as outras duas fases estacionárias apresentam fatores de assimetria de 1,1, ${ }^{25}$ indicando que a fase estacionária Zorbax Extend C18 não é apropriada. Porém ao se analisar uma mistura de solutos básicos em fase móvel ácida (a pH 2,5, com tampão fosfato $20 \mathrm{mmol} / \mathrm{L}$ ) com cada uma das três fases estacionárias (Figura 18Sa, material suplementar), verifica-se que todas as três são apropriadas para analisar solutos básicos. $\mathrm{O}$ resultado inesperado se deve ao fato da análise ter sido feita em fase móvel ácida, mesmo com a fase estacionária Zorbax Extend C18, que apresenta alta atividade silanofílica apenas em fase móvel neutra. Por outro lado, quando a análise é feita com ácido fórmico 0,1\% (Figura $18 \mathrm{Sb}$, material suplementar), a fase estacionária XBridge C18 apresenta os piores resultados (reparar a alta assimetria da tripolidina e da nortriptilina). A Waters admite que suas fases estacionárias que utilizam tecnologia híbrida de pontes de etano (XBridge e Acquity UPLC BEH) fornecem baixa eficiência na análise de solutos básicos em fases móveis neutras, e que este problema foi resolvido com o desenvolvimento da tecnologia CSH. ${ }^{35}$ Desta forma, quando uma fase estacionária tiver de ser selecionada para certa aplicação, não se deve esperar que uma fase estacionária, para a qual um teste da literatura ou o catálogo do fabricante afirme que fornece altas eficiências e picos simétricos com tampão fosfato $20 \mathrm{mmol} / \mathrm{L}$, forneça altas eficiências e picos assimétricos em fase móvel ácida tamponada com ácido fórmico $0,1 \%$ e vice-versa.

Como já discutido no início desta revisão, o objetivo em RP-LC é obter a separação dos picos em que a seletividade é o fator que mais influencia a resolução. Por sua vez, a avaliação de fase estacionária baseada apenas no fator de assimetria e na eficiência de um soluto 
básico não fornece nenhuma informação a respeito da seletividade. Por exemplo, na Figura 2 se o foco do trabalho é apenas analisar o dextrometorfano, em um medicamento antigripal, a fase estacionária L-Column2 ODS é de longe uma melhor opção que as fases estacionárias YMC-Pack Pro C18 e TKS-GEL ODS-100V, que fornecem picos assimétricos para o dextrometorfano. Por outro lado, se o foco do trabalho é analisar uma mistura de antidepressivos tricíclicos, estas fases estacionárias fornecem melhor seletividade para o par amitriptilina-mianserina que a fase estacionária L-Column2 ODS. Suponhamos agora que o objetivo seja separar a amitriptilina da mianserina em um medicamento e que não seja possível utilizar as fases estacionárias YMC-Pack Pro C18 e TKS-GEL ODS-100V. Como poderia ser escolhida uma fase estacionária que apresente seletividade semelhante a uma destas duas fases estacionárias?

É possível identificar se uma fase estacionária apresenta seletividade similar ou distinta de outra fase estacionária (se uma fase estacionária $\mathrm{X}$ é ortogonal ou paralela a outra fase estacionária Y), comparando que fases estacionárias apresentam parâmetros cromatográficos similares para um determinado teste, por exemplo, as fases estacionárias YMC-Pack ODS-AQ, TSKGelODS-80TM, QS Uptisphere 3 HDO, Prontosil C18-AQ, TSKGelODS-80TS, Gemini C18, Synergi Max RP e Gemini NX C18 apresentam valores para os 6 parâmetros cromatográficos do teste de Tanaka, próximos aos valores da fase estacionária YMC-Pack Pro C18 (Tabela 2S, material suplementar) e, portanto, devem apresentar seletividades similares. ${ }^{69,79,80}$ Outros testes estão disponíveis gratuitamente na internet para identificar quais fases estacionárias apresentam seletividades semelhantes ou distintas..$^{25,87}$

\section{CONCLUSÕES}

Nos últimos 10 anos, foram desenvolvidas fases estacionárias preparadas com sílica isenta de contaminantes metálicos e com sílica híbrida e representam um grande avanço na análise de solutos básicos.

Quando for necessário escolher uma determinada fase estacionária para analisar solutos básicos, os testes de Tanaka e SRM 870 podem ser úteis e os resultados da avaliação de diversas fases estacionárias com estes testes se encontram disponíveis na literatura. ${ }^{25,27}$ No entanto, fases estacionárias que são indicadas por estes testes como adequadas para analisar solutos básicos podem não ser tão adequadas quando se utilizam fases móveis com baixas concentrações de tampão (>10 mmol/L) ou de ácido $(0,1 \%)$.

A concentração de tampão é um fator que afeta pouco a retenção em RP-LC e quanto menor a quantidade de silanóis livres na superfície da fase estacionária menor será o efeito da concentração de tampão sobre a retenção mas, no caso dos solutos básicos a baixas concentrações de tampão ou de ácido na fase móvel, mesmo com fases estacionárias preparadas com sílica isenta de contaminantes metálicos, pode resultar em fatores de retenção excessivos, assim como alta assimetria e baixa eficiência. ${ }^{1,18,55,69,70}$

Quando for necessário aumentar a resolução de solutos básicos, o pH da fase móvel é a primeira variável que deve ser explorada, uma vez que influencia fortemente a retenção de solutos ionizáveis, e o uso de fases móveis ácidas aumenta a retenção de solutos ácidos e o uso de fases móveis alcalinas aumenta a retenção de solutos básicos.

$\mathrm{O}_{\mathrm{w}}{ }_{\mathrm{w}}^{\mathrm{s}} \mathrm{pH}$ de fases móveis preparadas com tampões amino é menor que o $\mathrm{pH}$ da fase aquosa, enquanto o ${ }_{w}^{\mathrm{s}} \mathrm{pH}$ de fases móveis preparadas com tampões como fosfato e carbonato é maior que o $\mathrm{pH}$ da fase aquosa. Os ${ }_{w}{ }^{\mathrm{s}} \mathrm{pKa}$ de solutos básicos na fase móvel são menores que os pKa em fase aquosa e os ${ }_{w}{ }^{\mathrm{s}} \mathrm{pKa}$ dos solutos ácidos são maiores que os pKa em fase aquosa. Por estas razões, é possível manter os solutos desprotonados maximizando as interações hidrofóbicas a valores de $\mathrm{pH}$ (fase aquosa) iguais aos valores de $\mathrm{pKa}$ (em fase aquosa) dos solutos, ${ }^{67} \mathrm{e}$ que por causa da diferença do valor do ${ }_{w}^{5} \mathrm{pH}$ da fase móvel e da fase aquosa, que é usada para preparar a fase móvel quando se troca tampão fosfato ou carbonato por um tampão amino, os solutos ácidos serão mais retidos e os básicos serão menos retidos.

Por sua vez, o uso de amino tampões ao invés de tampões inorgânicos aumenta a vida útil das fases estacionárias, uma vez que as fases móveis preparadas com amino tampões têm menor ${ }_{\text {w }}^{\mathrm{s}} \mathrm{pKa}$ que fases móveis preparadas com tampões inorgânicos. A concentração do tampão na fase móvel tem um efeito muito menor sobre a degradação da fase estacionária do que a temperatura e o $\mathrm{pH}$ da fase móvel. As fases estacionárias que apresentam maior estabilidade em meio alcalino são preparadas com sílica híbrida e as fases estacionárias com maior estabilidade em meio ácido são preparadas com silanos, com grupos laterais volumosos, dificultando a clivagem da ligação $\mathrm{Si}-\mathrm{C}$, devido ao impedimento estérico dos grupos laterais volumosos.

\section{MATERIAL SUPLEMENTAR}

No material suplementar disponível em http://quimicanova.com.br, com acesso livre, em arquivo pdf, são ilustradas algumas partes discutidas no texto, na forma de figuras e tabelas.

\section{AGRADECIMENTOS}

À FAPESP, ao CNPq e à CAPES pelo apoio financeiro e bolsas.

\section{REFERÊNCIAS}

1. McCalley, D. V.; J. Chromatogr., A 2010, 1217, 858.

2. Welch, C. J.; Wu, N.; Biba, M.; Hartman, R.; Brkovic, T.; Gong, X.; Helmy, R.; Schafer, W.; Cuff, J.; Pirzada, Z.; Zhou, L.; Trends Anal. Chem. 2010, 29, 667.

3. McCalley, D. V.; Adv. Chromatogr. 2008, 46, 305.

4. Tonhi, E.; Collins, K. E.; Jardim, I. C. S. F.; Collins, C. H.; Quim. Nova 2002, 25, 616.

5. Silva, C. R.; Jardim, I. C. S. F.; Collins, C. H.; Airoldi, C.; Quim. Nova 2004, 27, 270.

6. Collins, C. H.; Silva, C. R.; Faria, A. M.; Collins, K. E.; Jardim, I. C. S. F.; J. Braz. Chem. Soc. 2009, 20, 604.

7. Faria, A. M.; Collins, C. H.; Jardim, I. C. S. F.; J. Braz. Chem. Soc. 2009, 20, 1385.

8. Maldaner, L.; Collins, C. H.; Jardim, I. C. S. F.; Quim. Nova 2010, 33, 1559 .

9. Borges, E. M.; Bottoli, C. B. G.; Collins, C. H.; Quim. Nova 2010, 33, 945.

10. Kazakevich, Y.; Lobrutto, R.; HPLC for Pharmaceutical Scientists, John Wiley \& Sons: Hoboken, 2007

11. Hinshaw, J. V.; LCGC North Am. 2010, 28, 952.

12. Hinshaw, J. V.; LCGC North Am. 2010, 28, 874.

13. Dolan, W. D.; LCGC North Am. 2011, 29, 318.

14. Maldaner, L.; Jardim, I. C. S. F.; Quim. Nova 2009, 32, 214.

15. Wu, N.;. Clausen, A. M.; J. Sep. Sci. 2007, 30, 1167.

16. Chiaradia, M. C.; Collins, C. H.; Jardim, I. C. S. F.; Quim. Nova 2008 , 31,623 .

17. Gosetti, F.; Mazzucco, E.; Zampieri, D.; Gennaro, M. C.; J. Chromatogr., A 2010, 1217, 3929.

18. Marchand, D. H.; Carr, P. W.; McCalley, D. V.; Neue, U. D.; Dolan, J. W.; Snyder, L. R.; J. Chromatogr., A 2011, 1218, 7110.

19. Vyňuchalová, K.; Jandera, P.; Anal. Lett. 2011, 44, 1640.

20. Németha, T.; Haghedoorena, E.; Noszálc, B.; Hoogmartensa, J.; Adams, E.; J. Chemometrics 2008, 22, 178

21. Lesellier, E.; West, C.; J. Chromatogr., A 2007, 1158, 329. 
22. Buszewski, B.; Kowalska, S.; Krupczynska, K.; Crit. Rev. Anal. Chem 2007, 35, 89.

23. Neue, U. D.; J. Sep. Sci. 2007, 30, 1611.

24. Sander, L.; Wise, S. A.; J. Sep. Sci. 2003, 26, 283.

25. http://www.usp.org/USPNF/columnsDB.html, acessada em Janeiro 2012.

26. Kimata, K.; Iwaguchi, K.; Onishi, S.; Jinno, K.; Eksteen, R.; Hosoya, K.; Arki, M.; Tanaka, N.; J. Chromatogr. Sci. 1989, 27, 721.

27. http://www.acdlabs.com/resources/freeware/, acessada em Janeiro 2012.

28. http://www.waters.com/waters/nav.htm?cid=513217, acessada em Janeiro 2012.

29. http://www.waters.com/webassets/cms/library/docs/720002861en.pdf, acessada em Janeiro 2012

30. http://www.chem.agilent.com/Library/selectionguide/Public/59904435EN.pdf, acessada em Janeiro 2012.

31. Kirkland, J. J.; Martosella, J. D.; Henderson, J. W.; Dilks Jr., C. H.; Adams Jr., J. B.; Am. Lab. 1991, 31, 22.

32. Dolan, J. W.; LCGC North Am. 2007, 25, 1014

33. Yang, X.; Dai, J.; Carr, P.W.; J. Chromatogr., A 2003, 996, 13.

34. Neue, U. D.; Tran, K. V.; Méndez, A.; Carr, P. W.; J. Chromatogr., A 2005, 1063, 35.

35. Fountain, K. J.; Hewitson, H. B.; Iraneta, P. C.; Morrison, D.; http://chromatographyonline.findanalytichem.com/lcgc/article/ articleDetail.jsp?id=728026\&pageID=1\&sk=\&date, acessada em Janeiro 2012.

36. Dolan, W. D.; LCGC North Am. 2011, 29, 236.

37. Claessens, H. A.; van Straten, M. A.; J. Chromatogr., A 2004, 1060, 23

38. Claessens, H. A.; Trends Anal. Chem. 2001, 20, 563.

39. Nawrocki, J.; J. Chromatogr., A 1997, 779, 29.

40. Neue, W. D.; Serowik, E.; Iraneta, P.; Alden, B. A.; Walter, T. H.; J. Chromatogr., A 1999, 849, 87.

41. Jacoby, M.; Chem. Eng. News 2008, 86, 17.

42. Cheng, Y.-F.; Walter, T. H.; Lu, Z.; Iraneta, P.; Alden, B. A.; Gendreau, C.; Neue, U. D.; Grassi, J. M.; Carmody, J. L.; O’Gara, J. E.; Fisk, R.; LCGC North Am. 2000, 18,1162.

43. Wyndham, K. D.; O’Gara, J. E.; Walter, T. H.; Glose, K. H.; Lawrence, N. L.; Alden, B. A.; Izzo, G. S.; Hudalla, C. J.; Iraneta, P. C.; Anal. Chem. 2003, 75, 6781.

44. http://www.waters.com/waters/nav.htm?cid=513767, acessada em Janeiro 2012.

45. https://solutions.shimadzu.co.jp/glc/whatsnew/tmp/geniminx.pdf, acessada em Janeiro 2012.

46. http://chromatographyonline.findanalytichem.com/lcgc/article/ articleDetail.jsp $? \mathrm{id}=547885 \&$ pageID $=1 \& \mathrm{sk}=\&$ date $=$, acessada em Janeiro 2012.

47. http://www.kromasil.com/technical_evidence/eternity/introduction.php, acessada em Janeiro 2012.

48. http://www.waters.com/waters/nav.htm?cid=10165804, acessada em Janeiro 2012.

49. Nawrocki, J.; Dunlap, C.; McCormick, A.; Carr, P. W.; J. Chromatogr., A 2004, 1028, 1 .

50. Nawrocki, J.; Dunlap, C.; Li, J.; Zhao, J.; McNeff, C. V; McCormick, A.; Carr, P. W.; J. Chromatogr., A 2004, 1028, 31.

51. Dai, J.; Yang, X.; Carr, P. W.; J. Chromatogr., A 2003, 1005, 63.

52. Hu, Y.; Yang, X.; Carr, P. W.; J. Chromatogr., A. 2002, 968, 17.

53. http://www.zirchrom.com/, acessada em Janeiro 2012.

54. Borges, E. M.; Silva, C. G. A.; Collins, C. H.; Microchem. J. 2010, 96, 120 .
55. Borges, E. M.; Collins, C. H.; J. Sep. Sci. 2011, 34, 1141.

56. Borges, E. M.; Collins, C. H.; J. Chromatogr., A 2011, 1218, 4378.

57. Borges, E. M.; Collins, C. H.; J. Sep. Sci. 2011, 34, 3011.

58. Borges, E. M.; Collins, C. H.; Chromatographia 2012, doi:10.1007/ s00216-011-5674-z.

59. Borges, E. M.; Collins, C. H.; J. Chromatogr., A 2012, doi: 10.1016/j. chroma.2012.01.001.

60. Dolan W. D.; LCGC Noth Am. 2010, 28, 1022.

61. Engelhardt, H.; Blay, Ch.; Saar, J.; Chromatographia, Suppl 2005, 62, S19.

62. Agrafiotou, P.; Ràfols, C.; Castells, C.; Bosch, E.; Rosés, M.; J. Chromatogr., A 2011, 1218, 4995.

63. Subirats, X.; Bosch, E.; Rosés, M.; J. Chromatogr., A 2009, 1216, 2491.

64. Subirats, X.; Bosch, E.; Rosés, M.; J. Chromatogr., A 2007, 1138, 203.

65. Buckenmaier, S. M. C.; McCalley, D. V.; Euerby, M. R.; J. Chromatogr., A 2003, 1004, 71.

66. Buckenmaier, S. M. C.; McCalley, D. V.; Euerby, M. R.; J. Chromatogr., A 2004, 1026, 251.

67. Walter, T.; Alden, B.; Fisk, R.; Gendreau, C.; Iraneta, P.; http://www. waters.com/waters/library.htm?cid $=511436 \&$ lid=1536788, acessada em Janeiro 2012.

68. Torres-Lapasió, J. R.; García-Alvarez-Coque, M. C.; Bosch, E.; Rosés, M.; J. Chromatogr., A 2005, 1089, 170.

69. Euerby, M. R.; McKeown, A. P.; Petersson, P.; J. Sep. Sci. 2003, 26, 295.

70. Chan Leach, D.; Stadalius, M. A.; Berus, J. S.; Snyder, L. R.; LCGC Int. 1988, 1,22 .

71. McCalley, D. V.; J. Chromatogr., A 2000, 902, 311.

72. Kirkland, J. J.; van Straten, M. A.; Claessens, H. A.; J. Chromatogr., A 1998, 797, 111.

73. Teutenberg, T.; Hollebekkers, K.; Wiese, S.; Boergers, A.; J. Sep. Sci. 2009, 32, 1262 .

74. Claessens, H. A.; van Straten, M. A.; Kirkland, J. J.; J. Chromatogr., A 1996, 728, 259.

75. Kirkland, J. J.; J. Chromatogr., A 2004, 1060, 9.

76. Trammell, B. C.; Boissel, C. A.; Carignan, C.; O’Shea, D. J.; Hudalla, C. J.; Neue, U. D.; Iraneta, P. C.; J. Chromatogr., A 2004, 1060, 153.

77. http://www.waters.com/webassets/cms/library/docs/720003820EN.pdf, acessada em Janeiro 2012.

78. Neue, U.; van Tran, K.; Iraneta, P. C.; Alden, B. A.; J. Sep. Sci. 2003, $26,174$.

79. Euerby, M. R.; Petersson, P.; LC-GC Eur. 2000, 13, 665.

80. Euerby, M. R.; Petersson, P.; J. Chromatogr., A 2003, 994, 13.

81. http://www.acdlabs.com/resources/freeware/, acessada em Janeiro 2012.

82. Davies, N. H.; Euerby, M. R.; McCalley, D. V.; J. Chromatogr., A 2007, 1138,65 .

83. Okusa, K.; Suita, Y.; Otsuka, Y.; Tahara, M.; Ikegami, T.; Tanaka, N.; Ohira, M.; Takahashi, M.; J. Sep. Sci. 2010, 33, 348

84. Visky, D.; Heyden, Y. V.; Ivany, T.; Baten, P.; De Beer, J.; Kovacs, Z.; Noszal, B.; Roets, E.; Massart, D. L.; Hoogmartens, J.; J. Chromatogr., A 2002, 977, 39 .

85. Rogers, S. D.; Tese de Doutorado, The Florida State University, USA, 2003, disponível em http://etd.lib.fsu.edu/theses/available/etd-08192004103718/unrestricted/Rogers_S.pdf, acessada em Janeiro 2012.

86. Claessens, H. A.; van Straten, M. A.; Cramers, C. A.; Jezierskab, M.; Buszewski, B.; J. Chromatogr., A 1998, 826, 135.

87. http://pharm.kuleuven.be/pharmchem/Pages/ccs.html, acessada em Janeiro 2012. 